\title{
A.JO'ГE
}

African Journal of Teacher Education

ISSN 1916-7822. A Journal of Spread Corporation

Volume $8 \quad 2019 \quad$ Pages 321-343

\section{Institutional conditions for preparing critically reflective TEFL teachers in the PGDT Program of three Ethiopian universities.}

\author{
Roba Danbi Wodessa \\ and \\ Dereje Tadesse Birbirso, \\ Bule Hora University, Bule Hora, Ethiopia \\ robadanbi@gmail.com \\ Haramaya University, Haramaya, Ethiopia \\ dttadesse@gmail.com
}

\begin{abstract}
This paper assesses the role played by the institutional context in the preparation of critically reflective TEFL teachers in the Postgraduate Diploma in Teaching (PGDT) program of Dilla, Haramaya, and Hawasa Universities, Ethiopia. It examines the extent to which structured opportunities for reflection are used in the three institutions. A combination of quantitative and qualitative research methodologies was employed for collecting information regarding reflective practice in the PGDT program of the three universities. Multilevel mixed-method sampling techniques were utilized to select participants. Data were collected using questionnaires, semi-structured interviews and observation, and interpreted using simple statistical analysis and descriptive narrative approach. The study shows that most of the participants lack sufficient theoretical and practical knowledge of reflective practice. It shows that structured opportunities for reflection were not created for student teachers to practice reflection. The researchers, therefore, recommend that the government, curriculum designers, teacher education institution, and teacher educators create a common understanding about the goal of the program, and deliberately setup some structured opportunities to promote reflection in the institutions.
\end{abstract}

\section{Key words}

Institutional context; PGDT program; reflection; reflective practice; structured opportunity 


\section{Introduction}

Since the launching of Education and Training Policy of 1994 (MOE, 1994), Teacher education program in Ethiopia has passed through several reforms in a bid to produce competent teachers for secondary schools. From 1991 to 2003 secondary school teacher education was offered within a four-year training program; from 2003 to 2010 another program which was offered within three-year timing was launched called Teacher Education System Overhaul (TESO); and in 2011, the currently ongoing Postgraduate Diploma in Teaching (PGDT) was launched (MOE, 1994; MOE, 2003; MOE, 2009). The PGDT program, designed to be completed within a oneyear duration, gives due attention to theories and practice of teaching. Unlike TESO, the PGDT program mainly focuses on pedagogical and practical issues in teaching; it assumes that its registrant student teachers would have acquired enough content knowledge during their undergraduate studies. It was founded on the education and training policy guidelines of Federal Government Ministry of Education which aimed at improving teachers' and facilitators' skills through a national program of teacher professional development (MOE, 2015). The PGDT program pays considerable attention to pragmatism or reflective practice approach with the intention of making teaching the profession of choice. The curriculum framework of PGDT program (MOE, 2009) states:

This program has made this issue a top priority and intends to build a teacher education program that is based on pragmatism and reflective practitioner orientations. Change in Ethiopian school necessitates graduates that challenge the existing status quo through reflection and changing the existing culture could be possible by involving the teachers in self-study and practice (MOE, 2009, p. 5).

Accordingly, to achieve the proposed goal of the program the Ministry of Education decided to include relevant foundation courses and core concepts in the curriculum. These include, School and Society, Psychological Foundation of Learning and Development, Teaching in Multicultural Setting, Secondary School Curriculum and Instruction, Teachers as reflective Practitioners, and English language skills, and Subject Area Methodology (MOE, 2009). In addition to the single course on reflective practice, these courses are all framed with reflective activities.

The program simultaneously offers both theories of teaching and practicum (practice of teaching). The practicum is organized into three phases: a week of intensive school observation 
before starting the training, 30\% of the credit hours of each course allocated to practical works and projects in schools, and independent teaching practice (MOE, 2009, p. 13). One of the course requirements for this program is titled 'Teachers as Reflective Practitioners' (TRP). In this program, the concept of reflection for pedagogical and content learning and professional development received more attention than in former reforms. Its curriculum framework, policy guidelines, policy mission statements, and all courses in the program stress the concept of reflective practice so that student teachers might be able to examine their assumptions, practices, teaching/learning theories, and educational settings (MOE, 2009).

However, the current authors believe that beyond the rhetoric articulated in the curriculum framework of the PGDT program, the extent to which theory and practice are integrated must be examined. In fact, great effort has been devoted to the study of the PGDT program since its establishment as a teacher education program in two modalities - summer and regular (Margo, 2014; Mekonnen, 2017; Gemachu et al, 2017; Awayehu, 2016). Most extant studies on the program investigated the practical aspects of the program to see the integration of theory and practice. Some employed experimental case studies to investigate whether student teachers were taught how to practice critical reflective skills (Birbirso, 2014; Gebremedin, 2013). Nevertheless, there are still some interesting and relevant problems to be addressed. For example, the findings by both Gebremedin (2013) and Birbirso (2014) indicate that both teachers who graduated from the program and student teachers in the program lack the basic skills of reflective practice. The question arises as to why; what challenges are there to the practice of reflection; what critical ingredients does the program lack which availability may help student teachers to have a firm understanding of the reflective practice?

Perhaps attention has not been given to some suggestions of Dewey (1933), Freire (1972), Brookfield (2017, 1995), Day (1999), Loughran (2005), and Farrell (2013) and other scholars of reflective practice regarding the implementation of reflective practice. For example, these scholars believe that it is impossible to empower student teachers to challenge traditional and existing values without creating a welcoming environment for them. Furthermore, in order to become reflective practitioners, the individuals should cultivate personal qualities of openness to new information, a willingness to be challenged and a deep hope that change is possible (Fook and Gardner, 2007). This implies that successful introduction of reflective practice in teacher education requires a right institutional context and a ready student mindset. Therefore, the 
purpose of this study is to investigate whether the EFL PGDT programs of the three universities have such an enabling context for student teachers to practice reflection during formal training.

The following were the research questions investigated:

- To what extent is the condition of reflective practice established in EFL focused PGDT program in order to promote reflection?

- How do student teachers, instructors, and program coordinators think about these conditions in their institutions?

\section{Conceptual Framework}

While reflective practice in teacher education in general and in the pre-service teacher education program is not without its own shortcoming, it has nonetheless been highly recommended for teacher-learning and development. Many scholars agree that reflective practice is a better means to help student teachers understand the potential impediments to their progress during their learning and teaching practices (Grant and Zeichner, 1984; Taylor, 2006; Çimer, Çimer, and Vekli, 2013; Day, 2001). However, the implementation of reflective practice is not a simple task. It requires the facility of enabling factors (Day, 1999; Richards, 2011). In this paper, these enabling factors, which will be discussed in the following sections, are referred to as the institutional context (structured opportunities) for reflection.

\section{Institutional Context}

The condition of the institution plays an important role either to impede or ensure the progress of the implementation of reflective practice in teacher education. Minott (2009) for example acknowledged that for professional learning to occur via the act and processes of reflection, the context in which reflective practitioners operate must be supportive of this kind of learning. For example, the assumption that reflective practice is too simple to practice, resistance to reflection on the part of teachers themselves, and the blocks to an ethical-political reflection that teaching environments and institutions erect are impediments in the path of proper reflective practice (Markham, 1999 cited in Minott, 2009). A teacher education institution where different modes of reflective practice is under consideration will afford student teachers the safe enabling environment to explore their own beliefs, assumptions, and values about their practice. Such an environment will promote student teachers' confidence to talk and write about their beliefs and 
practice as well as engage in classroom observations to compare their beliefs and practices (Farrell, 2013).

Maxwell (2009) has observed that an institution with a busy and disorganized schedule could not use reflective practice for its professional learning and would be unable to contribute to teachers' professional growth. Cole (1997) also remarked that reflective practice needs to receive institutional support as a legitimate form of professional development as reflective skills such as critical thinking and self-examination never come naturally but rather call for the provision of set-times for reflection, thinking about the process, and consistent focus. Therefore, program designers must include in their programs all the elements making for an appropriate learning atmosphere and structured opportunities for reflection that include time and place, shared understanding of the theory, a culture of inquiry and learning through action, and an effective reward system (Brookfield, 1995; Day, 1999; Maxwell, 2009, emphasis is added). We now examine each of these elements.

\section{Time Set aside for Reflection}

Loughran (2006) notes that learning through the process of reflection can face difficulties of time constraints. He writes:

The 'when' of reflection (the time of reflection in relation to the pedagogical experience) influences the learning that might be drawn from that experience. Three time frames for reflection are discernible: before, during and after an experience. At each of these times one's thoughts and actions may be considerably different so that what one learns will be influenced accordingly (Loughran, 2006, P. 17 emphasis is original).

He suggests the importance of time (the when of reflection) to learn from experience through the setting of a different timeframe for reflection. This indicates that learning through reflective practice needs considerable attention and conscious planning. Similarly, for reflective practice in teacher education to be a priority, how to effectively integrate it with and implement it in learning activities must also be a priority. This assigns student teachers some time to examine their learning, practice, assumption, and beliefs. Maxwell (2009) asserts that ignoring time for reflection prevents student teachers from staying focused, finding a clear picture to follow, and from examining their emotional difficulties. But if the time is carved out formally for reflection, student teachers are likely to do reflective thinking. 


\section{Shared Understanding on the Goal of the Program}

Martin-Beltran and Peercy's (2014) study of teacher learning as activity shaped by a greater network of relationships revealed that teaching goals, shared artifacts, administrative support, school norms and division of labor were important features that consolidate collaborative spirit among school teachers. As a result, for the better implementation of reflective practice in the teacher education program, having a shared understanding of the goal and the intended outcome of the program is very important.

In the same way, teachers who teach in different contexts need to acquire the appropriate contextual knowledge that will enable both teacher educators and student teachers to have shared goals of the institution to function in those contexts. A teacher education institution can create a school culture made up of teaching methods and relationships within the classroom and the school as fixed behavior that student teachers go through for their reflective practice. Richards (2011) emphasized that such fundamental techniques and behaviors should be communicated to all concerned staff and learners.

Learning to teach, therefore, must involve shared understanding or knowledge about classroom dynamics and the rules and behaviors specific to particular settings. This understanding helps the student teachers to be socialized into a professional culture with its own goal, shared values, and norms of conduct (Richards, 2011). Pre-informing student teachers about the objective of the program, and the theory of reflective practice, what skills it requires, and how it is implemented reduces challenges that could hinder both student teachers and teacher educators from implementing the new guideline for reflective practice in our case.

\section{Culture of Critical Inquiry}

Maxwell (2009) argues that the value gained from reflection depends on the type of questions asked. He says that the better the questions, the more knowledge you gain from your thinking. However, the type of questions one asks or reflects on depends on the culture of inquiry that the institution allows for its staff and student teachers. That means the culture of teacher education institutions plays a pivotal role in supporting student teachers' stance towards inquiry, which is one of the attributes of reflective practice in teaching that distinguishes reflective practitioners from their non or less reflective colleagues (Day, 1993). Also as noted by Valli et al. (2006), "As the institution discussed desirable features of the program, an agreement emerged that the core 
courses should build teachers' capacities to inquire into their teaching practices and student learning (P. 97)". Thus, for student teachers to ask a relevant question about institutional setting in general and classroom dynamics in particular, the existence of a trusting and encouraging condition to support their ability and willingness to inquire into different problems without any feeling of negative consequence is a necessity. In trustful atmosphere, according to Brookfield (1995), people know that public disclosure of private errors or critical questions will not lead to negative consequences. The teacher education institution is therefore in the proper position to initiate the culture of inquiry by removing cultural inhibitors and creating an opportunity for the student to critically question existing status quos and predetermined teaching-learning principles.

\section{A Separate Place for Reflection}

Setting a secure place for reflection is another important element in a teacher education program that embraces the reflective practice. Maxwell (2009) also argues that as much as any kind of thinking, reflection requires an isolated place and unorganized time and reflection simply don't mix. Some people feel that reflection can be done on a bus while going home or at a cafeteria while dirking tea or coffee (Brookfield, 1995). However, to develop the culture of reflection in teacher education institution there should be a place officially reserved for the practice of reflection. An absence of this element would otherwise provide an excuse for teacher educators and student-teacher to ignore the new approach of teaching.

\section{Immersion in Practice-based Learning}

Another principle for the embracement of reflective practice in the teacher education program is immersing student teachers in practice-based learning. Maxwell (2009) again says that writing down the good thoughts that come out of one's reflective thinking has value, but nothing helps you to grow like putting one's thoughts into action. To do that, student teachers and teacher educators must be intentional. This is one way that helps teachers to bridge the gap between theory and practice (Loughran and Hamilton, 2016). From this student teachers can learn how to have perspective within context, how to connect their knowledge with action, and how to plan and get direction for future concerns. This process becomes an invaluable tool for a teacher's personal growth (Maxwell, 2009). 


\section{Rewarding Critical Thinking}

Creating the reward system for active involvers is also an important condition to enhance reflective practice in teacher education programs (Brookfield, 1995). Once the appropriate structured opportunity for reflection has been created in the teacher education program and the old patterns of behavior have become deconstructed, the resulting new atmosphere leads people to act differently. This promotes desirable professional habit in which reflection become normal in the teaching-learning setting. The most important thing to start with is the prevailing rewards system. Where a focus on important critical skills is supported by a reward system-praise, giving of responsibility, promotion, certifying, etc.,--reflection becomes a great deal of professional habit in the institution (Brookfield, 1995; Day, 1999; Maxwell, 2009).

\section{Collaborative Learning}

Finally, reflective practice can be instigated in the context of collaborative work which helps both teacher educators and student teachers to reflect on their experience and to experiment with alternative approaches to teaching and learning. As noted by Johnson(2009),

From a sociocultural perspective, teacher cognition originates in and is fundamentally shaped by the specific social activities in which teachers engage. Thus, teachers' knowledge and beliefs are constructed through and by the normative ways of thinking, talking, and acting that have been historically and culturally embedded in the communities of practice in which they participate (as both learners and teachers) (p. 17)

The clue in this quote is the ability of social activities to shape those who engaged in it; in this case student teachers. Freire (2005) also strongly believes that substantive educational change cannot occur without conversation and collaborative learning. Similarly, though Brookfield $(1995,2017)$ believes that isolated individual reflection is a necessary condition in the empowering of teachers through the self-discovery of their practical knowledge, he calls for collaborative reflection. He believes that unless we are involved in those activities with critical friends we produce or repeat the old culture as it is.

Horn (2000) suggests that critical conversations facilitate new educational designs, creative problem-solving, and personal and collective critical reflection on theory and practice. The most important attribute of this kind of conversations in facilitating learning is their ability 
to empower those who participate in them. When participants gain knowledge through the process of collaborative learning or through conversation on their experiences of relationships, visions, emotions, and self-esteem, their knowledge of critical reflection increases (Horn, 2000). Therefore, the attainment of personal practical knowledge, critical reflection, is most effective when it occurs through the medium of critical conversation with other friendly professionals.

\section{Research Methodology}

\section{Study Sites}

This study was conducted at three of the higher learning institutions, Dilla, Haramaya, and Hawasa universities, Ethiopia. These sites were selected based on the opportunity created by their relative nearness to the researchers' work and study stations (cf. Holliday, 2007). Dilla and Hawasa Universities, respectively, are the institutions where the researchers have been working collaboratively with some of the schools' English language staff on issues of curriculum review for undergraduate and graduate programs. Haramaya University, on the other hand, is where the researchers work and Haramaya the city where they live.

The population of the study was all the prospective trainees enrolled in Postgraduate Diploma in Teaching (PGDT) in the three universities in the year 2017/18 of regular modality. The study employed a multilevel mixed-method sampling technique conducted at three different institutions and among participants of the Postgraduate Diploma in Teaching Program. The study considered only the regular modality of the 2018 enrollments.

\section{Sampling Techniques}

The participants involved in the quantitative part of this study were student teachers of EFL PGDT program of three universities. To establish a sampling frame, the researchers obtained and carefully evaluated the respective list of the population of the three universities to ensure that they are correct and complete. The information gathered for this purpose showed that the size of the population of English focus student teachers on duty in the 2017/2018 academic year was for Haramaya University (HrU) 72, Hawasa University (HU) 78, and Dilla University (DU) 45. The total number of the participants was 195 . However, the actual number of the population when the study took place was $164(\mathrm{HU}=67, \mathrm{DU}=45$, and $\mathrm{HrU}=52)$. Finally, Yamane's formula (i.e. $\mathrm{n}$ $\left.=\mathrm{N} / 1+(\mathrm{N})(0.05)^{2}\right)($ Israel, 1992) was applied to determine sample size. Accordingly, 143 
samples were selected through simple random sampling techniques. Purposive sampling technique of the non-probability sampling method was used to select 20 participants for the qualitative part of the study. The best cases among the population of the study were selected based on their roles, responsibility, the course offered, and affiliation to the home department (Patton, 2015). All the participants gave relevant information about the context of the EFL focus PGDT program.

\section{Instruments for Data Collection}

A descriptive research design with a concurrent mixed (qualitative and quantitative) approach was employed to get a general picture of the current teacher training program in Dilla, Haramaya, and Hawasa Universities. The data for this study were direct account that participants provided in response to the research questions directed to them. Because the research employed mixed-method, different data collection instruments such as the close-ended question, the semistructured interview, and the observation were utilized for this study. The questionnaire was administered to 143 student teachers and the interview to 12 student teachers (from the same population for the quantitative part of the study), 5 teacher educators and 3 program coordinators. The field observation of the classroom and institutional settings was made at two universities where the researchers stayed for a long period of time for this study. All data collected through interviews and observation were documented in the researchers' diary and recorded on a video camera. During the interview, an attempt was made to probe the participants' responses more deeply to get the latest information related to the teaching profession (Cohen et al., 2011).

\section{Methods of Data Analysis}

In this study, both quantitative and qualitative analytical procedures were used for the analysis. Descriptive statistics, frequency, and percentage have been employed to analyze the quantitative data. The data collected through semi-structured interviews using a video camera was transcribed from participants' native languages (Amharic \& Afaan Oromoo) into English. Then the descriptive narrative analysis approach was used to summarize the data collected through interviews and observation field notes. The data were coded based on Saldana's (2013) coding system. The first major theme was identified after a thorough reading of the excerpts; secondly, sub-themes were identified; and finally, propositional statements were developed. To identify 
individuals who provided the comments, identification codes were assigned to each participant (e.g. Int-interview, St1-student no.1 at 8:30/May, 2018). The major theme identified in the study was institutional context and some sub-themes were categorized under the major theme. Finally, the interpretation was made based on the propositional statement or theme developed from the topic coded. The purpose was to learn how participants felt, experienced, and practiced the concept of reflective practice during their professional training. The results of both qualitative and quantitative data were combined in the discussion section for a better understanding of the findings.

\section{Results}

The major theme of this study was the critical role of institutional conditions in implementing and maintaining reflective practice. The findings mainly focus on student teachers' awareness about reflective practice and the incidence of structured opportunity for reflection (such as meeting, safety, reserved setting (time and place), strategic encouragement (rewarding), cooperative learning, modeling, and posing critical questions). The analysis was guided by the idea that reflective practice needs an enabling environment where practitioners could safely practice reflection as a carefully structured and disciplined process (John Dewey 1938). Consequently, the role that teacher education institutions could play to maintain the implementation of reflective practice was investigated and discussed below.

\section{The Role of Institutional Condition to Maintain Reflective Practice}

The findings on how much emphasis was exerted to improve institutional conditions to maintain reflective practice in PGDT program were presented in two separate sections: Background Information about Reflective Practice and Structured Opportunity for Reflection. In the first section, student teachers' background knowledge of reflective practice is discussed.

\section{Student Teachers' Background Knowledge of Reflective Practice}

To investigate the participants' background knowledge of reflective practice, among other questions posed was, "Have you had any information about reflective practice before joining PGDT program?" The purpose was to examine the link between the undergraduate program and teacher education program in the institutions. To assess this, descriptive statistics such as frequency, percentage, and non-parametric inferential statistics, i.e. Chi-square statistics test (to 
compare the difference between/among frequency distribution of the response) was utilized. The overall measurement results are summarized in Table 4.1 below.

Table 1: Frequency distribution of participants' perception about reflective practice and chisquare test result

\begin{tabular}{|c|c|c|c|c|c|}
\hline Variables & Response category & Frequency & Percent & $\begin{array}{l}\text { Chi- } \\
\text { square }\end{array}$ & p-value \\
\hline \multirow{3}{*}{$\begin{array}{l}\text { Have you had any } \\
\text { information about RP } \\
\text { before you join } \\
\text { PGDT? }\end{array}$} & Yes, I have & 26 & 21 & \multirow{3}{*}{43.460} & \multirow{3}{*}{.000} \\
\hline & No, I haven’t & 100 & 79 & & \\
\hline & Total & 126 & 100 & & \\
\hline \multirow{5}{*}{$\begin{array}{l}\text { How did you hear } \\
\text { about RP? }\end{array}$} & $\begin{array}{l}\text { From all courses in } \\
\text { the program }\end{array}$ & 9 & 7 & \multirow{5}{*}{125.360} & \multirow{5}{*}{.000} \\
\hline & $\begin{array}{l}\text { From the program } \\
\text { coordinators }\end{array}$ & 22 & 18 & & \\
\hline & From the course TRP & 74 & 59 & & \\
\hline & Other sources & 21 & 16 & & \\
\hline & Total & 126 & 100 & & \\
\hline \multirow{3}{*}{$\begin{array}{l}\text { Do you believe you } \\
\text { have better knowledge } \\
\text { about RP? }\end{array}$} & Yes, I believe & 106 & 84 & \multirow{3}{*}{58.698} & \multirow{3}{*}{.000} \\
\hline & No, I don't believe & 20 & 16 & & \\
\hline & Total & 126 & 100 & & \\
\hline \multirow{5}{*}{$\begin{array}{l}\text { What new things did } \\
\text { you learn from the } \\
\text { course TRP? }\end{array}$} & Teaching method & 20 & 16 & \multirow{5}{*}{87.460} & \multirow{5}{*}{.000} \\
\hline & Reflecting on practice & 76 & 60 & & \\
\hline & Assessing learning & 22 & 18 & & \\
\hline & Nothing was new & 8 & 6 & & \\
\hline & Total & 126 & 100 & & \\
\hline
\end{tabular}


Table 1 shows that of the 126 participants who completed the questionnaire, the majority of the respondents $100(70 \%)$ replied that they came to the program without having information about reflective practice. Only 25 participants (21\%) said they came to the program with information about reflective practice. The chi-square test value, $\mathrm{X}^{2}(\mathrm{Df} 1)=43.460, \mathrm{P}<0.05$ proved there is a significant difference between the frequency of the response category. This test revealed that the majority number of respondents joined the PGDT program without knowing reflective practice.

In response to Questions 2 (in the same table), 74 (59\%) of the participants heard about reflective practice from the course titled Teachers as a Reflective Practitioner, 22(18\%) heard about it from the coordinators during orientation, and 21(17\%) heard from other sources (independent reading). A significant difference is observed among the frequency response categories. This shows student teachers responded differently to the question they were asked of how they heard about reflective practice. The largest number of participants replied that the course Reflective Practice was the source of their information. This appears to be that student teachers heard about reflective practice from an individual course designed for that purpose rather than from all courses described in the curriculum framework. Respondents were also asked if they believed they had acquired a better knowledge of the reflective practice. The larger number 106 (84\%) replied that they had, while $20(16 \%)$ replied that they did not acquire a better knowledge of reflective practice. There is a statistically significant difference between frequencies of the response categories. The larger number of respondents believed that they had acquired a better knowledge of the reflective practice.

We wanted to examine what new skill student teachers learned from the course as elements of the reflective practice. Most respondents (76/60\%) stated that how to reflect on practice was new to them, while few $(22 / 18 \%)$ saw how to assess the learning process as something new that they have learned from the course. The chi-square test value there is a significant difference among the frequencies of response categories. This shows that from the course Teacher as a Reflective Practitioner, reflecting on practice was new for most student teachers.

Of the 14 interviewed student teachers, almost all participants reported that they came into the program without having information about reflective practice. The majority of those who responded had no information about the existence of the PGDT program, and most of them had 
no interest to be a teacher. The original plan they had for their future was for some job opportunities other than teaching. To illustrate this, one individual stated that:

I did not like the teaching profession before I joined this program. However, after I went through the program, some courses made me love the teaching profession. It gave me a clue how to interact with society, which helped me to see teaching beyond classroom activities (IntStF1, 2018).

In this interview script phrases such as 'before I join this program', and 'after I went through the program'show the process of change in the participant's perception of the teaching profession. She remarked that what she gained from the training (the PGDT program) was a change in her perception of the teaching profession. In the same way, all teacher educators and program coordinators of all three universities admitted that the trainees of the PGDT program came in only with subject matter knowledge. The researchers, as instructors in these schools of undergraduate students, are witnesses that pedagogy courses are not offered to the students.

Thus, it can be concluded that the respondents had no information about reflective practice when they joined the PGDT program, but they heard about it and learned how to reflect on practice after they joined the Program. However, field and classroom observations confirmed that though the reflective practice was taught, student teachers could not translate this knowledge into practice. For example, their conception of reflective practice was as classroom presentations and doing assignments and engaging in discussions with friends.

\section{Structured Opportunities for Reflective Practice}

This second section presents the extent to which the structured opportunity is recognized and valued in the three institutions for the practice of reflection. The variables such as meeting for reflection, strategic encouragement (reward), guarantee (freedom and safety), modeling, collaborative learning and time and place fixed for reflection purpose were tested using different measurement scales (YES/NO, Likert/Likert type scales). The result was analyzed using frequency distribution and chi-square test statistics. The findings are summarized in the following table. 
Institutional conditions for preparing critically reflective TEFL teachers in the PGDT Program of three Ethiopian universities.

Table 2: Frequency of respondents' opinion about structured opportunity for reflection

\begin{tabular}{|c|c|c|c|c|c|c|}
\hline No & Variables & Response category & Frequency & Percent & Chi-square & $\mathrm{p}$-value \\
\hline \multirow{3}{*}{1} & Have you ever & Yes, we have met & 13 & 10 & \multirow{3}{*}{79.365} & \multirow{3}{*}{.000} \\
\hline & \multirow{2}{*}{$\begin{array}{l}\text { met for } \\
\text { reflection } \\
\text { purpose }\end{array}$} & No, we haven't met & 113 & 90 & & \\
\hline & & Total & 126 & 100 & & \\
\hline \multirow{6}{*}{2} & \multirow{6}{*}{$\begin{array}{l}\text { Structured } \\
\text { opportunity for } \\
\text { reflection was } \\
\text { deliberately } \\
\text { allowed }\end{array}$} & Never & 98 & 78 & \multirow{6}{*}{270.111} & \multirow{6}{*}{.000} \\
\hline & & Rarely & 18 & 14 & & \\
\hline & & Sometimes & 7 & 6 & & \\
\hline & & Usually & 3 & 2 & & \\
\hline & & Certainly & - & - & & \\
\hline & & Total & 126 & 100 & & \\
\hline \multirow{4}{*}{3} & \multirow{4}{*}{$\begin{array}{l}\text { Theory taught } \\
\text { was linked with } \\
\text { practice }\end{array}$} & Yes, it was practiced & 19 & 15 & \multirow{4}{*}{78.905} & \multirow{4}{*}{.000} \\
\hline & & $\begin{array}{l}\text { No, it wasn't } \\
\text { practiced }\end{array}$ & 18 & 14 & & \\
\hline & & I am not sure & 89 & 71 & & \\
\hline & & Total & 126 & 100 & & \\
\hline
\end{tabular}

In Table 2 above, 13(10\%) of the respondents said that they had conducted a meeting for reflection purposes and $113(90 \%)$ of the participants said they didn't meet for reflection. The chi-square test value, $\left.X^{2}(\operatorname{Df} 1)=79.365, p>0.05\right)$ proved there is significant difference among the frequencies of the response categories.

The second variable in the above table contained five items (modeling, strategic encouragement, critical questioning, collaborative learning, and fixed time and pace) which later, during analysis, transformed into one variable structured opportunity for reflection to measure the extent to which this value was practiced by using five-point Likert type scales. Before 
transforming the items into one variable, the consistency of each item was tested using Cronbach's Alpha coefficient (Gaur and Gaur, 2009). The Cronbach's alpha value for the items was significant at .728 which is greater than .70 , the cut-off point for items reliability (Nunnally, 1978). Therefore, these items are reliable to be transformed into one variable. The result showed that most participants, $98(78 \%)$ reported that the opportunity for reflection was never recognized in the institution, and only very few respondents $18(14 \%)$ replied that there are structured opportunities for reflection. Thus, almost all participants negated the use of modeling, strategic encouragement, critical questioning, collaborative learning, and fixed time and place for the deliberate use of reflection. The chi-square test value $X^{2}(D f=4, N=126)=270.111, p>0.05$ indicate the significant difference among the frequencies of response categories. Thus, it appears that structured opportunities for reflection were roughly valued as preconditions for reflective practice in the three universities selected for this study.

In the same way, the participants were asked to respond Yes or No to whether the theory of reflective practice taught in class was applied to practice. Accordingly, the larger number of participants $(71 \%)$ responded that they were not sure while very few participants (15\%) responded Yes and (14\%) No, respectively. The chi-square test value $\mathrm{X}^{2}(\mathrm{Df} 2)=78.905, \mathrm{P}>0.05$ indicate that there is a statistically significant difference among the categories of the response. Thus, it appears that most of them wanted to remain neutral regarding the question of implementation of theory into practice. This implies that the theory taught in the class was not succinctly applied to practice.

Similarly, more than $85 \%$ (11) of those who interviewed reported that there was no special treatment done to facilitate reflection. When they were asked about types of teachinglearning employed in the PGDT program, all participants noted that the PGDT teaching/learning program was not different from the undergraduate program's teaching-learning process. For example, one-to-five group discussion was used as a collaborative learning method. The researchers observed that the student teachers did not consider one-to-five-group as a proper method of teaching. This might be due to less value attached to it compared to other teaching/learning methods. This negative attitude towards one-to-five group method, thus, impeded the student teachers' active participation in collaborative learning. 
On the other hand, the result obtained from the interview with teacher educators revealed that even though teacher educators/instructors tried hard to facilitate reflective practice, student teachers had no interest and sometimes did not attend the class. So, instructors blamed student teachers for constraints to implementing reflection. However, from teacher educators' responses, it is clear that structured opportunities for reflection such as time, place, collaborative learning, rewarding and posing critical questions were not created for the practice of reflection. Finally, respondent program coordinators were of the view that opportunities for reflection are already fixed in the course contents and that it is up to the teacher educators to rearrange and apply them. They listed available opportunities for reflection, such as practicum phases, action research, classroom discussion, and assignments. Only one participant reported an absence of formally selected reflective practice learning opportunities. Likewise, during observation, it was noticed that the coordinators did not have much close contact with student teachers and teacher educators. There was no teaching model agreed upon to be used to enhance student-teacher critical reflection skills, and there was no close follow up to determine whether the program was running as planned in the curriculum.

\section{Discussion}

The purpose of this study was to discuss the role of institutional condition to prepare critically reflective teachers in Ethiopia's PGDT program. In the study, attention was paid to student teachers' background knowledge of reflective practice before joining the PGDT program and the structured opportunity used to maintain the culture of reflection in the institutions selected for this study. The findings show that the reformation of the curriculum for the PGDT program is not supported by institutional culture and not grounded in the values that promote reflection. As discussed in the foregoing sections of this study report, the findings show an unpromising institutional context to promote reflection in the teaching-learning process of the PGDT program of the three universities.

The findings show that student teachers had no prior background knowledge about reflective practice. This finding is consistent with the study of Areaya (2017) which shows that teaching-learning in most Ethiopian schools was mainly based on teacher-centered traditional methods. This means the process of reflective practice is not rooted in its principles down to 
secondary education and undergraduate program's teaching-learning processes. An important implication of this finding is that there is a very rough integration between theory and practice.

Another important finding was that the goal of the program or the prioritization of the notion of reflective practice was not clearly understood by both student teachers and teacher educators. None of the three institutions oriented their student teachers to have a shared understanding of the importance of critical reflection and how it can be applied in professional learning. This finding confirms the idea discussed by Day (1999) that learning goals should be explicitly negotiated among student teachers, instructors, and management to meet the perceived needs of the program. A possible explanation for this result may be the lack of adequate training on the foundational issues of reflective practice for teacher educators.

It is also noteworthy that in the TEFL PGDT program of the three universities the planned structured opportunity for reflection was scarcely utilized to maintain the culture of reflective practice. As a result, the values that are needed for the practice of reflection were not developed in the institutions alongside the curriculum framework and program reformation. Hence, the program is only reformed at paper or curriculum level while this reformation is not aligned with institutional cultures, including student teachers' and teacher educators' beliefs about the teaching-learning process. This coincides with what Loughran and Hamilton (2016) repeatedly expressed in their writings that to use any reflective tools, student teachers must have model tools as a scaffolding stage to write their own. For example, Birbirso (2012) used his innovative reflective tools during weekend sessions to intervene in student teachers' underdeveloped reflective skills. In doing this, he resolved the problem related to a shortage of time to practice reflection. So, this substantiates the argument of this research that there should be separated time and place to initiate both teacher educators' and student teachers' motivation for the deliberative use of reflection.

In general, all the findings discussed in this paper show that the three institutions failed to prepare the necessary platform for student teachers to practice learning based on the reflective practice approach in the PGDT program. It might be this core factor that sustained the problem of the student teachers' inability to reflect and understand the concept of reflection beyond their very shallow meaning. Day (1999) and Richards (1998) remarked on the need for decisiveness of the match between a reform and institutional conditions to achieve the imaginative goal set in the 
reform. The implication is that the priority given for reflective practice in the curriculum framework needs the instructors', student teachers', and managements' common understanding of the goal of the program. This was not realized in the three institutions that were selected for this study. Reflection was not yet supported by instructors' commitment of time and effort to major learning endeavors specified in the curriculum. This shows that the problem occurred because the idea of reflective practice was not negotiated between curriculum designers and practitioners. It seems that this misunderstanding between curriculum designers and practitioners contributed to the poor implementation of reflective practice, and this might have accounted for student teachers' underdevelopment of critical reflective skills.

\section{Conclusion}

The objective of this study was to investigate the role of the institutional context in promoting critical reflective practice in EFL teacher preparation program of three Ethiopian universities: Dilla, Haramaya, and Hawasa. Based on the results presented, it can be concluded that student teachers of three universities under the study came to the PGDT program without knowing the concept of reflective practice which might have helped them to choose the teaching profession on their bases and make the training easy along the way. In addition, the institutions overlooked the structured opportunities for reflection such as modeling, conferencing, collaborative learning, separated time and place, safety, and a rewarding system. We also conclude that the PGDT program curriculum reformation was not grounded in institutional contexts. This seems to be because the initiative for curriculum reformation started from the top without been based on the need of student teachers and teacher educators at the bottom. Therefore, at the time of implementation, the resistance sparked from the instructors and student teachers and the existing culture of the teaching-learning process in the institutions resulted in the low level of reflection achieved by the EFL student teachers of the PGDT program of the three universities.

\section{Recommendation}

We recommend firstly that student teachers should come to the PGDT program with sufficient knowledge of reflective practice from their undergraduate studies. Secondly, structured opportunities for reflection such as modeling, holding meeting/conference, collaborative learning, separated time and place, safety, and a rewarding system must be given sufficient attention to promote the culture of reflective practice in EFL teacher education program. 
Otherwise, the PGDT program should be replaced by other teacher education models which provide a longer study time. This will help student teachers to have enough time to learn the theory and engage in reflective practice. Finally, we recommend that prospective researchers conduct action research to provide background knowledge and structured opportunities for reflection in the university.

\section{References}

Amera, S. B. (2016). Student Teachers' Reflective Learning Practices within Secondary School Teacher Education Curriculum Implementation Process at Bahir Dar University. Unpublished PhD dissertation: AAU

Areaya, S. (2017). Secondary Teacher Education in Ethiopia: Top-Down Reforms and Policy Implications. The Ethiopian Journal of Education Vol. XXXVI No. 1 June 2016

Awayehu, M. (2016). The New Secondary School Teacher Education Modality in Ethiopia: Challenges and Implications. Middle Eastern \& African Journal of Educational Research, Issue 20, Year 2016

Birbirso, D.T. (2009). A Practitioner Inquiry into Pre-Service EFL Reflective Practicum of Haramaya University: A Condition of Inability to Reflect and Determinants of Effective Reflection. unpublished $\mathrm{PhD}$ dissertation: Addis Ababa

Birbirso, D.T. (2012). Reflective Practicum: Experience of the Ethiopian Context. Reflective Practice, 13:6, 857-869, DOI: 10.1080/14623943.2012.697886

Brookfield, D. (1995, 2017). Becoming a Critically Reflective Practitioner (2 ${ }^{\text {nd }}$ ED.). JOSSEYBASS

Çimer, A, Çimer S, \& Vekli G. S., (2013). How does Reflection Help Teachers to Become Effective Teachers? International J. Educational Research Vol.1 Issue 4, ISSN:23067063133

Cole, A., L. (1997). Impediments to Reflective Practice Towards a New Agenda for Research on Teaching. In Teachers and Teaching; Theory and Practice Volume, 3 (1)

Creswell, J. (2003). Research design: Qualitative, Quantitative, and Mixed Methods Approaches $\left(2^{\text {nd }} E D\right.$. $)$. Thousand Oaks, CA: Sage

AJOTE Vol. 8 (2019), 321-343 
Day, C. (1993). Reflection: A Necessary but not Sufficient Condition for Professional Development. British Educational Research Journal Vol.19, No.1

Day, C. (1999). Researching Teaching through Reflective Practice. Falmer press, London

Day, C. (2001). Professional Development and Reflective Practice: Purposes, Processes and Partnerships. The Course named "Understanding and Developing Reflective Practice" Readings. School of Education, University of Nottingham, Nottingham

Day, R. (n.d). Models and the Knowledge Base of Second Language Teacher Education. University of Hawai 'i Working Papers in ESL, Vol. 11, No. 2, pp. 1-13.

Dewey, J. (1933). How We Think: A Restatement of the Relation of Reflective Thinking to the Education Process. Boston: MA, D. C, Heath.

Farrel, T. (2007). Reflective Language Teaching: From Research to Practice. London: Continnum

MOE (1994). Federal Democratic Republic Government of Ethiopia. Education and training policy. Addis Ababa.

Freire, P. (1970, 1983, 2000). Pedagogy of the Oppressed: 30th Anniversary Edition

Gaur, S. \& Gaur S. (2009). Statistical Methods for Practice and Research: A Guide to Data Analysis Using SPSS. SAGE Publication Inc

Gemechu, E, Shishigu A, Michael K, Atnafu M, \& Ayalew Y. (2017). Reforms of Teacher Education in Ethiopian: A Historical Analysis Research. Journal of Science Vol. 5(2), 1-6, February (2017)

Grant \& Zeichner (1984). On Becoming a reflective teacher.

Hinchey, P. H. (2004). Becoming a Critical Educator: Defining a Classroom Identity, Designing a Critical Pedagogy: New York

Holliday, A. (2007). Doing and Writing Qualitative Research (2ED.). SAGE publication Horn, R. A. (2000). Teacher talk: A Post-Formal Inquiry into Educational Change 
Hussein, J. (2011). Impediments to Educative Practicum: The Case of Teacher Preparation in Ethiopia. Research in Post-Compulsory Education, 16:3, 333-355, DOI: $10.1080 / 13596748.2011 .602244$

Israel, G. D. (1992). Determining Sample Size. Fact Sheet PEOD-6: University of Florida

Jay, J. K. (2003). Quality Teaching Reflection as the Heart of Practice. Scarecrow Press. United States of America.

Johnson, K. E. (2009). Second Language Teacher Education: A Sociocultural Perspective. Routledge: The Pennsylvania State University

Leavy, P. (2017). Research Design: Quantitative, Qualitative, Mixed Methods, Arts-Based, and Community-Based Participatory Research Approaches. A Division of Guilford Publications, Inc. United States of America

Loughran, J. \& Hamilton M. (2016). International Handbook of Teacher Eduation Vol.1. Springer Science-Business Media: Singapore.

Loughran, J. (2005). Developing Reflective Practice: Learning about Teaching and Learning through Modelling. The Falmer Press, USA

Martin-Beltran, M. \& Peercy M. (2014). Collaboration to Teach English Language Learners: Opportunities for Shared Teacher Learning. Teachers and Teaching, 20:6, 721-737, DOI: $10.1080 / 13540602.2014 .885704$

Mekonnen, G. T. (2017). The Current Teacher Education Programs in Ethiopia: Reflection on Practice. Academic Journal: Educational Research and Reviews Vol. 12(6), pp. 366372, 23 March, 2017: DOI: 10.5897/ERR2017.3172

Minott M., A. (2009). Supporting Reflective Teaching via Schools' Culture: A Framework Utilizing Tierney's understands of schools' culture

MoE (2003). Teacher education system over whole (TESO): Hand-book. Addis Ababa

MoE (2009). Curriculum framework for secondary school teacher education program in Ethiopia, Post Graduate Diploma in Teaching (PGDT). Addis Ababa.

Nunan, D. (1999). Research Methods in Language Learning. Eighth printing. Cambridge: CUP. 
Institutional conditions for preparing critically reflective TEFL teachers in the PGDT Program of three Ethiopian universities.

Pallant, J. (2007). SPSS Survival Manual: A Step by Step Guide to Data Analysis using SPSS for Windows ( $3^{r d}$ ED.). Open university Press

Patton, M. (1990): Qualitative Evaluation and Research Methods. Newbury Park, CA: SAGE Publications.

Saldana, J. (2013). The Coding Manual for Qualitative Researchers (2 ${ }^{\text {nd }}$ ED.). SAGE

Schon, D. (1983). The Reflective Practitioner: How Professionals Think in Action. Aldershot: Ashgate

Schon, D.A. (1987). Educating the Reflective Practitioner: Towards a New Design for Teaching and Learning in the Profession. San Francisco, CA: Jossey-Bass.

Taylor, B. (2006). Reflective Practice: A Guide for Nurses and Midwives (2 ${ }^{\text {nd }}$. ED.). Open University Press

Teka M. (2009): Evaluation of implementation of the paradigm shift in EFL teacher education in Ethiopia. Unpublished PhD Dissertation. Addis Ababa University

Valli, L., van Zee E., Rennert-Ariev P, Mikeska J, Catlett-Muhammad S, \& Roy P. (2006). Initiating and Sustaining a Culture of Inquiry in a Teacher Leadership Program: Teacher Education Quarterly, Summer 200

VanMannen, J. (1977). Linking Ways of Knowing with Ways of Being Practical. Curriculum Inquiry, 6(2), 205-208. 